\title{
Starved versus alluvial river bedforms: an experimental investigation
}

\author{
Gaetano Porcile ${ }^{1}$, Paolo Blondeaux ${ }^{1}$, Marco Colombini $^{1}$ \\ ${ }^{1}$ Department of Civil, Chemical and Environmental Engineering - University of \\ Genova
}

Via Montallegro 1, 16145 Genova, Italy

\begin{abstract}
Laboratory experiments were conducted to investigate the formation of river bedforms under sediment supply-limited conditions, i.e. when a motionless substratum is bared by the dynamics of the mobile sediments. Three series of experiments were organized in a laboratory flume by fixing all the hydrodynamic and morphodynamic parameters but varying the thickness $\Delta$ of the initial layer of mobile sediments which covers the rigid bottom of the flume. At the end of all the experiments, which lasted for the same amount of time, the formation of transverse sand dunes was observed. For decreasing $\Delta$, the rigid bottom of the flume was bared progressively earlier during the experiment and the measurements showed a clear tendency of the bedforms to lengthen, i.e. to increase their crest-to-crest distance. Moreover, under strong supply limitation, the two-dimensional transverse dunes turned into three-dimensional barchanoid forms and into isolated barchan dunes characterised by an abrupt reduction in bedform heights. A two-dimensional Fourier analysis of the bottom profile was performed, providing the amplitude of the main streamwise and spanwise harmonic components of the bottom morphology as a function of $\Delta$.
\end{abstract}

\section{Introduction}

In many natural environments, morphological patterns, that are commonly observed when motionless substrata are entirely covered by mobile sediments, may differ from those which are generated when the mobile sediments are insufficient to cover an underlying rocky bed or, more generally, a layer of immobile sediments. Isolated bedforms, which migrate over flat rigid (motionless) terrains, have been largely observed in aeolian environments and their geometric and kinematic characteristics are consistently different from those of bedforms observed along the deserts where sand is profuse (Allen, 1968; Howard et al., 1978; Wippermann and Gross, 1986). Field surveys seem to indicate that for similar conditions, the crest-to-crest distance (sometimes termed chord) of the bedforms characterized by sediment starvation is consistently larger than that of the morphological patterns which are generated where the sediment is abundant. In both panels of Figure 1, in the upper parts of the photos there is more availability of sediment than in the lower parts and the crest-to-crest distances of the desert dunes are conversely larger in the lower parts than in the upper ones.

A similar trend is observed in subaqueous marine environments where the sediment is mobilized by the oscillatory flow generated by tidal waves. For example Le Bot and Trentesaux (2004) showed that the sand waves, generated by oscillatory tidal currents in the English Channel close to the southern end of the "South Falls" bank, can be divided into two morphologically contrasted sectors. In the North-West sector, the mobile sediment (a mixture of sand and gravel) completely covers a pebble lag which is not mobilized by the tidal current. Here, tidal dunes are

http://mc.manuscriptcentral.com/esp

This article has been accepted for publication and undergone full peer review but has not been through the copyediting, typesetting, pagination and proofreading process which may lead to differences between this version and the Version of Record. Please cite this article as doi: $10.1002 /$ esp. 4800 


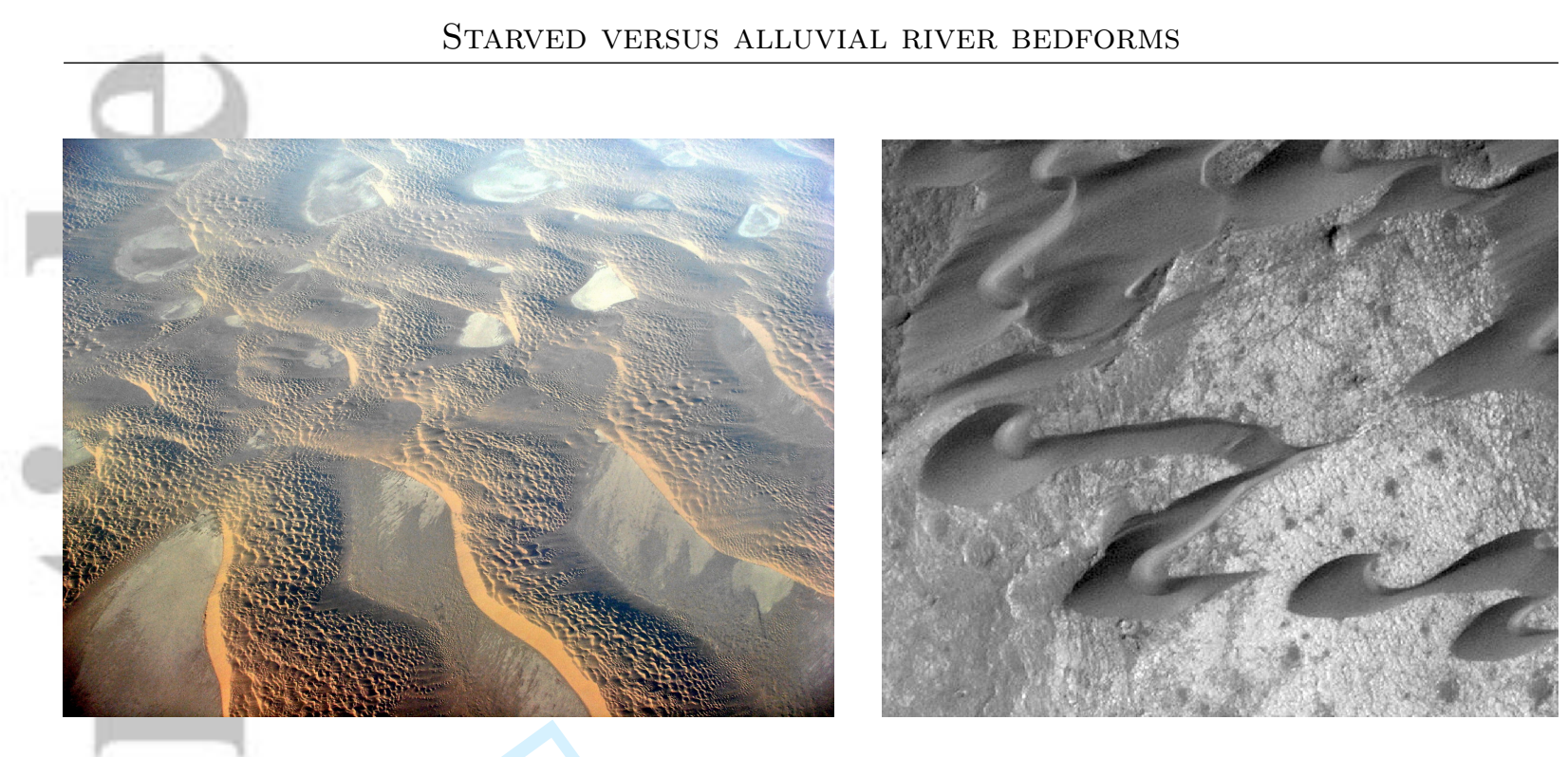

Figure 1: Left panel: Dunes of the Taklamakan Desert (credit: photo by Jay). Right panel: photo of sand dunes observed on the surface of Mars (credit: photo by NASA).

typical of an environment rich of mobile sediment (i.e. alluvial bedforms) and characterised by wavelengths of the order of hundreds of metres. In contrast, in the South-East sector, mobile sediment is present only in the form of a sequence of isolated sandy mounds of finite extent in the transverse direction that migrate over the pebble lag (i.e. starved bedforms). The averaged crest-to-crest distance of the sandy mounds is significantly longer than the wavelength of the sand waves generated by the same tidal currents in the North-West sector (see Figure 2).

It must be pointed out that only few observations of starved bedforms generated by steady currents in subaqueous environments are available and measurements do not indicate a clear trend. Carling et al. (2000) described the geometry of the bedforms observed in a supply-limited reach of the Rhine river (Germany), showing the presence of different morphological patterns: ripples, small dunes and large dunes. Their data suggest that the crest-to-crest distance of the small dunes changes as the bedforms move from an immobile gravel layer to the stoss and lee sides of the large dunes where mobile sediments are largely available. In particular, similarly to the observations of Sophie et al. (2000) and Le Bot and Trentesaux (2004) the crest-to-crest distance of the small dunes becomes longer when they move over the lag deposit. However, the laboratory measurements carried out by Tuijnder et al. (2009) seem to indicate the opposite: bedform size (both height and length) decreases as the volume of mobile fine sediment decreases and the immobile coarse bottom is bared.

Furthermore, in both aeolian and marine environments, a definable suite of starved bedforms develops (Venditti et al., 2017). In the Celtic Sea, where sandy patches overlay gravel lags, Kenyon (1970) distinguished marine sand ribbons, barchanoid sand waves and isolated dunes depending on the thickness of the sand cover and the strength of the forcing tidal currents. A similar sequence of bedforms is observed in fluvial environments (Kleinhans et al., 2002). Rivers typically show an abrupt transition from gravel to sandy bottoms as channel slopes decrease and, in many cases, seasonal and perennial gravel-bed rivers exhaust the supply of sediment their streams can entrain. In such cases, the finer sediment is mobilised as bedload transport while the mean grain size becomes coarser at the bed surface and, as such, poorly sorted river beds subject to periods of low flows undergo a transient degradation until they are fully armoured (Parker et al., 1982). When an armour layer develops and finer sediment is still available, a definable suite of starved bedforms can be observed. As the sediment supply 


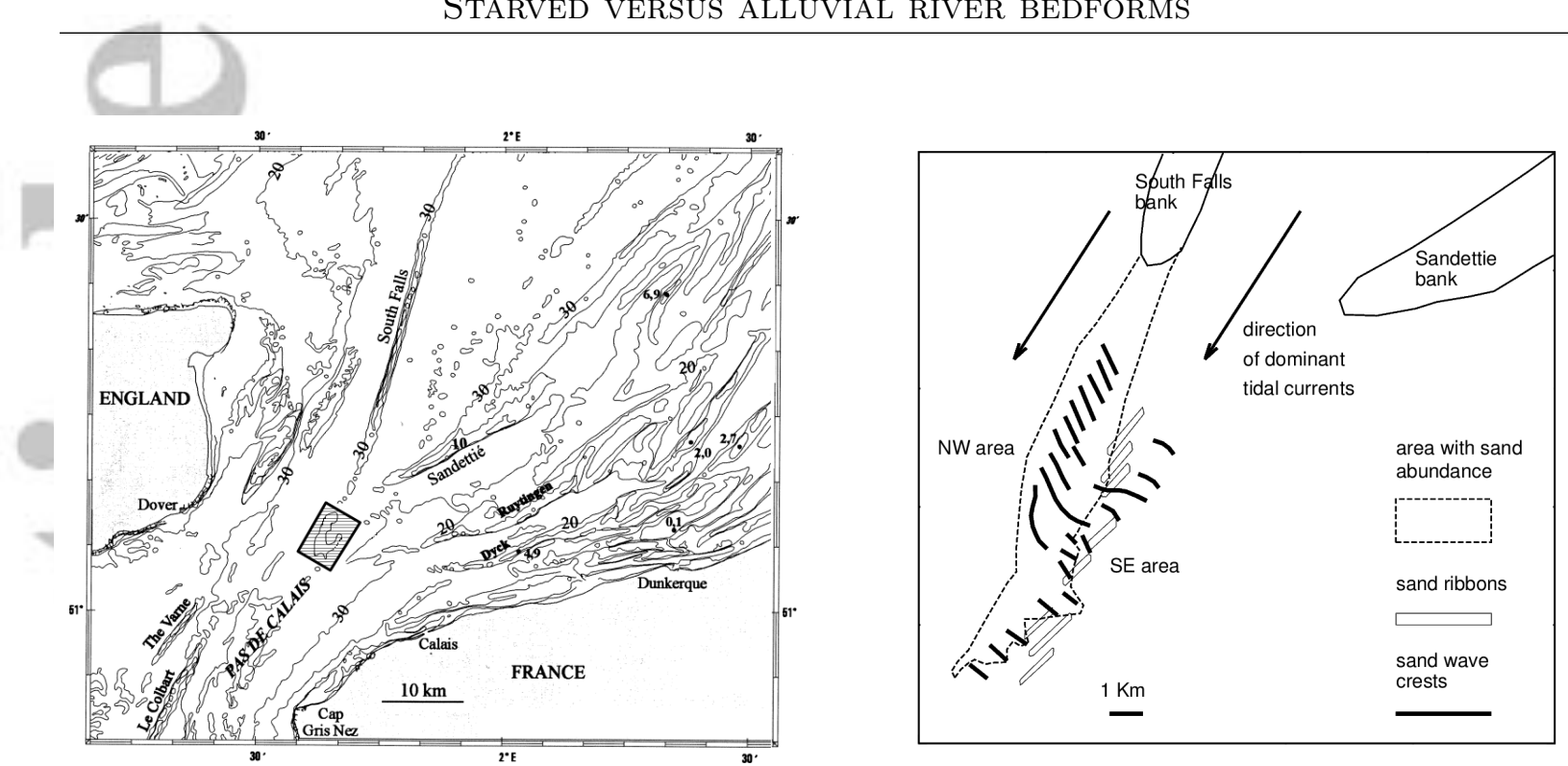

Figure 2: Left panel: Location of the sand wave field observed by Le Bot and Trentesaux (2004) in the English Channel between Calais and Dover, close to South Falls and Sandettie banks. The dashed rectangle represents the study area. Right Panel: Sketch of the measured sand wave crests. The broken line encloses an area rich of mobile sediment. Outside this area, pebble lags are observed (the data were provided by Sophie Le Bot, private communication).

from upstream increases, a gradual transition occurs from longitudinal sand ribbons to threedimensional barchans that eventually coalesce onto amorphous sandy mounds, ultimately leading to the appearance of two-dimensional transverse dunes (Kleinhans et al., 2002). By means of a very simple phenomenological experiment, Venditti et al. (2017) revealed that this sequence of bedforms emerges in steady currents as the sediment supply increases. In particular, it is the volume of sediment supply that controls the type of the emerging pattern.

The laboratory experiments described in the following were planned to provide further data on the effects of supply limitation (sediment starvation) on the formation of sand dunes generated by steady currents in subaqueous environments. Three sets of experiments were organized, keeping constant in each series all the flow and sediment parameters other than the thickness of the layer of sediment available for transport, thus allowing for a consistent comparison between the morphology of the starved bedforms and that of the alluvial bedforms. The duration of the experiments was kept fixed in order to analyse the effects on the dune geometric characteristics of the variations of the volume of mobile sediments only.

In the next section we describe the experimental apparatus and the experimental procedure. Experimental measurements are summarised in Section 3, while the results are discussed in Section 4. Conclusions are drawn in the final section.

\section{Apparatus and experimental procedure}

The experiments were arranged in a laboratory flume (12 m long, $0.4 \mathrm{~m}$ wide, $0.3 \mathrm{~m}$ deep) mounted on a beam, the slope of which was kept constant and equal to $0.15 \%$. The water flowed in the flume from a head tank filled by a $100 \mathrm{~mm}$ pipe line equipped with a $70 \mathrm{~mm}$ flow nozzle in order to measure the flow discharge. A sluice gate was placed at the end of the flume to control the water level in order to generate a uniform flow along the channel according to a rating 
curve established through some preliminary fixed-bed tests. Indeed, in all these preliminary tests, the free surface and the bed were remarkably parallel, up to the accuracy of the water level measurements $(<1 \mathrm{~mm})$. The initial water depth (i.e. the averaged difference between the elevation of the free surface and that of the top of the sand layer) was set at the beginning of each experiment according to the rating curve. Note that the bedform appearance and the related increase of the flow resistance led to a small increment of the mean water depth during the experiments.

Well sorted sand grains characterised by a mean diameter $d$ equal to $1.12 \mathrm{~mm}$ were glued on the flume bottom, thus creating a rough bed. At the beginning of each experiment, the same sand was uniformly spread over the bottom creating a layer of constant thickness $\Delta$ throughout the flume. Different experiments were made, starting from a relatively thick flat layer of mobile sand and progressively decreasing the layer thickness. The shear stress induced by the flowing water on the sandy bottom was large enough to cause the movement of the sediment across the entire flume and to generate bed features. Clouds of sand occasionally swirled off the crests of the bedforms but no suspended load was observed.

Each experiment was stopped after 30 minutes and the bottom configuration was measured (Figure 3). This duration was chosen on the basis of some preliminary mobile-bed tests which showed that, after such time, the crests of the bedforms could be readily identified under both supply-limited and alluvial conditions. The channel section suitable for the measurement of the bed morphology was approximately the downstream half of the channel (test section), where the irregularities of the incoming flow and the related upstream scour did not affect the formation of the morphological patterns. An estimate of the average height $h$ and length $\lambda$ (crest-to-crest distance) of the bedforms was obtained by identifying them using a standard mean up-crossing technique throughout the aforementioned test section. Such procedure can become questionable for three-dimensional bedforms, when the definition of crests and troughs is less clear. Hence, a detailed topographic survey of the bed was acquired by laser scanning. In particular, the Imager $5006 \mathrm{i}$ phase-based laser scanner, manufactured by Zoller + Frohlich, was used to measure the bottom profile from three different measuring stations, thus obtaining three sets of values of the bottom elevation which were interpolated on a regular grid by means of a MATLAB routine. The accuracy of the measurement procedure was quite high and the measurements of the bed elevation were affected by an error smaller than $1 \mathrm{~mm}$, mainly due to the random position of the sediment grains.

A two-dimensional Fourier analysis was employed to gain information on the periodicity of the measured bottom topography in both the streamwise and the spanwise directions. Data were mirrored with respect to one bank to handle diagonal fronts, so that the first transverse mode turns out to have a wavelength which is twice the channel width corresponding to an alternate bar pattern. Moreover, a stretch of the channel about $4 \mathrm{~m}$ long was selected in the streamwise direction so as to include only complete bedforms. This condition makes the length of the selected stretch slightly different from one experiment to another. The employed discrete Fourier transform transforms the array of sampled bottom elevations $\eta[m, n]$ into the array $H[k, l]$ that describes the harmonic content of the two-dimensional measured bottom configurations. The two-dimensional discrete Fourier transform reads

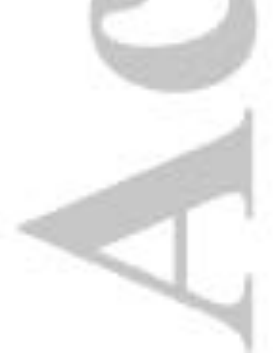

$$
H[k, l]=\frac{1}{2 N M} \sum_{m=0}^{M-1} \sum_{n=0}^{2 N-1} \eta[m, n] e^{-i \frac{2 \pi m k}{M}} e^{-i \frac{2 \pi n l}{2 N}}+\text { c.c. }
$$




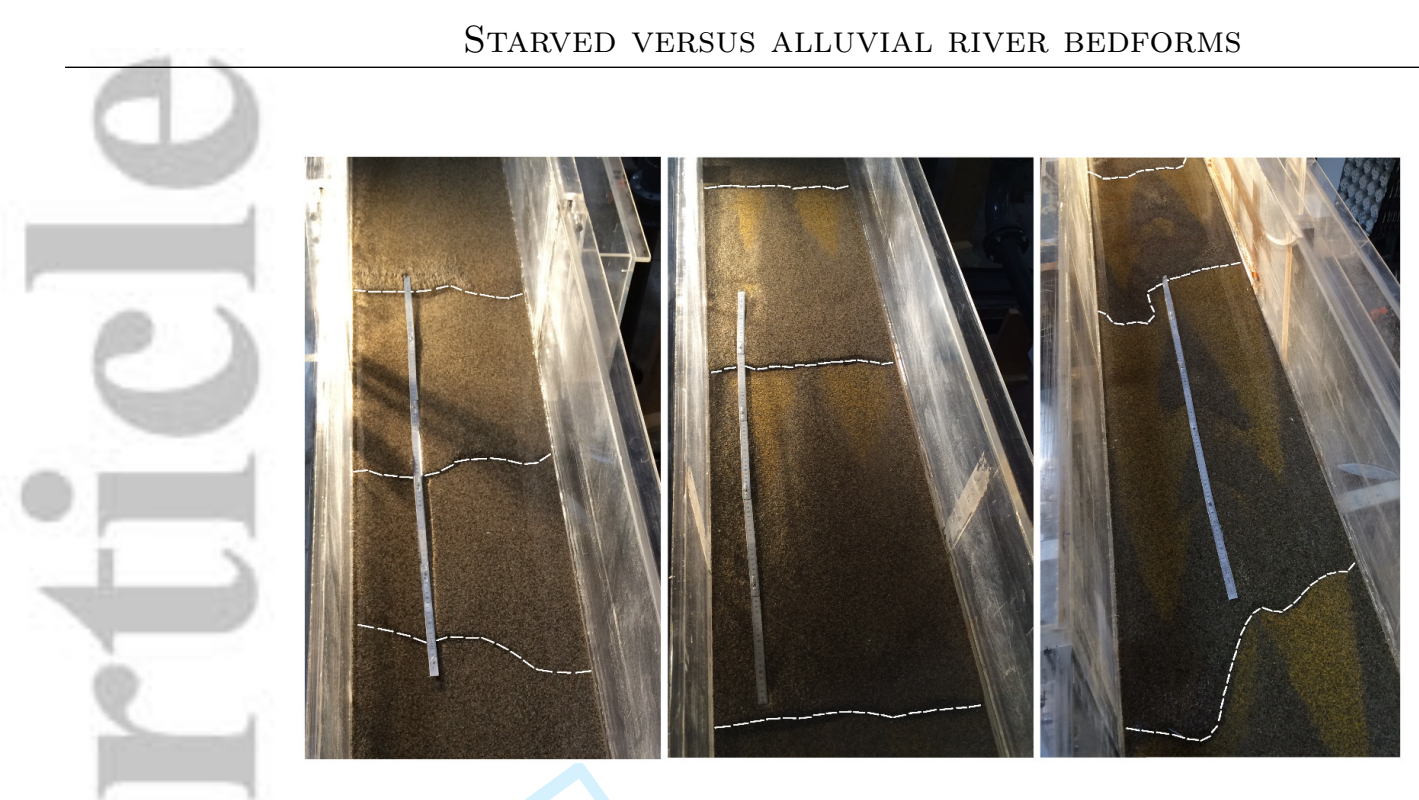

Figure 3: From left to right top views of the laboratory flume after 30 minutes from the beginning of the experiment S1N1, S1N4 and S1N5. The photos clearly show the bottom topography and the presence of the dunes, the crests of which are highlighted by dashed white lines. A stick 1 metre long allows a rough estimate of the crest-to-crest distances.

and the Fourier coefficients are given by

$$
\eta[m, n]=\sum_{m=0}^{M-1} \sum_{n=0}^{2 N-1} H[k, l] e^{+i \frac{2 \pi m k}{M}} e^{+i \frac{2 \pi n l}{2 N}}+\text { c.c. },
$$

where $M$ and $N$ are the numbers of the samples respectively in the streamwise and spanwise direction, while $k$ and $l$ represent respectively the streamwise and spanwise harmonics, c.c. indicates the complex conjugate of the quantity that precedes it.

\section{Experimental results}

Three series of experiments were performed. As shown in Table 1, each series comprised five experiments characterised by the same values of flow rate $Q$ and depth $H$, but decreasing values of the thickness $\Delta$ of the initial sand layer superjacent the rigid bottom of the laboratory flume. Table 1 provides also the values of the average fluid velocity $U$, the Froude number $F r$, the Chézy coefficient $C$, the length $L$ of the channel stretch to which the two-dimensional Fourier analysis was applied, the average height $h$ of the measured bedforms and their average crest-to-crest distance $\lambda$.

Figure 4 shows the sequence of scans of the bottom configurations observed through the downstream stretch of the channel at the end of each experiment. The crests of the patterns can be readily identified; the lengthening of the bedforms and their increasing irregularity with a decreasing initial sand layer thickness is clearly visible in each series of experiments as soon as the rigid bottom of the flume is exposed. The data also show that, for the smallest value of the initial sand layer thickness, the strong irregularity of the bottom configurations results into the appearance of three-dimensional bedforms. Most of the final bottom configurations are characterised by the presence of a longitudinal sand ridge along the channel axis, which is particularly evident in the first series. The mechanism which gives rise to these longitudinal sand ridges is presumably related to the existence of secondary cellular flows in the plane perpendicular 
to the channel axis which are generated by the imbalance of the normal Reynolds stresses in the cross-sectional plane and in particular in the corners of the rectangular section (Nezu and Nakagawa, 1984).

The bottom elevation with respect to the rigid bottom of the flume measured along downstream selected stretches of the channel is represented in Figure 5,7 and 9 for each experiment of the first, second and third series, respectively. The left panels of these figures show the bottom profiles recorded at a distance of $10 \mathrm{~cm}$ from the right sidewall of the flume, so as to minimise the effect of the sand ridge at the centerline. The right panels of these figures show the histograms of the distribution of the bed elevations, which provide a measure of how frequently the rigid bottom of the flume is exposed and allow for a rough evaluation of the average height of the bedforms. The top-left panel of Figure 5 shows the bottom profile across the selected stretch of experiment S1N1, which displays the typical triangular shape of alluvial dunes with a gently sloping stoss side and a steep lee side. Similar bottom profiles were observed at the end of all those experiments during which the amplitude of the emerging bedforms was not large enough to bare the rigid bottom of the flume. Differently, at the end of those experiments in which the emergence of the bedforms led to rigid bottom exposure, the geometric characteristics of the resulting bottom profiles changed, displaying bump-shaped starved dunes with steep stoss and

Table 1: Summary of the hydraulic conditions and dimensionless parameters of each experiment and the averaged height $h$ and wavelength $\lambda$ (crest-to-crest distance) of the bedforms observed throughout a selected flume stretch of streamwise length $L$.

\begin{tabular}{|c|c|c|c|c|c|c|c|c|c|c|}
\hline Series & $\begin{array}{c}Q \\
{\left[l s^{-1}\right]}\end{array}$ & $\begin{array}{c}H \\
{[\mathrm{~cm}]} \\
\end{array}$ & $\begin{array}{c}U \\
{\left[\mathrm{~ms}^{-1}\right]}\end{array}$ & $\begin{array}{l}F r \\
{[-]}\end{array}$ & $\begin{array}{c}C \\
{[-]} \\
\end{array}$ & Exp. & $\begin{array}{c}\Delta \\
{[\mathrm{cm}]}\end{array}$ & $\begin{array}{c}L \\
{[m]}\end{array}$ & $\begin{array}{c}h \\
{[\mathrm{~cm}]}\end{array}$ & $\begin{array}{c}\lambda \\
{[m]}\end{array}$ \\
\hline & 20.0 & 11 & 0.45 & 0.48 & 14.70 & $S 1 N 1$ & 2.5 & 4.5 & 1.04 & 0.47 \\
\hline & 20.0 & 11 & 0.45 & 0.48 & 14.70 & $S 1 N 2$ & 2.0 & 4.0 & 1.04 & 0.47 \\
\hline & 20.0 & 11 & 0.45 & 0.48 & 14.70 & $S 1 N 3$ & 1.5 & 3.8 & 1.04 & 0.47 \\
\hline & 20.0 & 11 & 0.45 & 0.48 & 14.70 & $S 1 N 4$ & 1.0 & 3.8 & 1.20 & 0.65 \\
\hline & 20.0 & 11 & 0.45 & 0.48 & 14.70 & $S 1 N 5$ & 0.5 & 4.1 & 0.70 & 0.92 \\
\hline & 22.5 & 11 & 0.51 & 0.53 & 14.83 & $S 2 N 1$ & 2.5 & 4.0 & 1.36 & 0.52 \\
\hline & 22.5 & 11 & 0.51 & 0.53 & 14.83 & $S 2 N 2$ & 2.0 & 4.2 & 1.36 & 0.53 \\
\hline & 22.5 & 11 & 0.51 & 0.53 & 14.83 & $S 2 N 3$ & 1.5 & 4.6 & 1.40 & 0.58 \\
\hline & 22.5 & 11 & 0.51 & 0.53 & 14.83 & $S 2 N 4$ & 1.0 & 4.7 & 1.45 & 0.68 \\
\hline & 22.5 & 11 & 0.51 & 0.53 & 14.83 & $S 2 N 5$ & 0.5 & 4.0 & 0.98 & 0.95 \\
\hline & 25.0 & 12 & 0.52 & 0.53 & 14.98 & $S 3 N 1$ & 2.5 & 4.7 & 1.35 & 0.49 \\
\hline & 25.0 & 12 & 0.52 & 0.53 & 14.98 & $S 3 N 2$ & 2.0 & 4.3 & 1.41 & 0.54 \\
\hline & 25.0 & 12 & 0.52 & 0.53 & 14.98 & $S 3 N 3$ & 1.5 & 4.5 & 1.47 & 0.60 \\
\hline & 25.0 & 12 & 0.52 & 0.53 & 14.98 & $S 3 N 4$ & 1.0 & 4.5 & 1.52 & 0.73 \\
\hline & 25.0 & 12 & 0.52 & 0.53 & 14.98 & $S 3 N 5$ & 0.5 & 4.5 & 0.90 & 1.10 \\
\hline
\end{tabular}



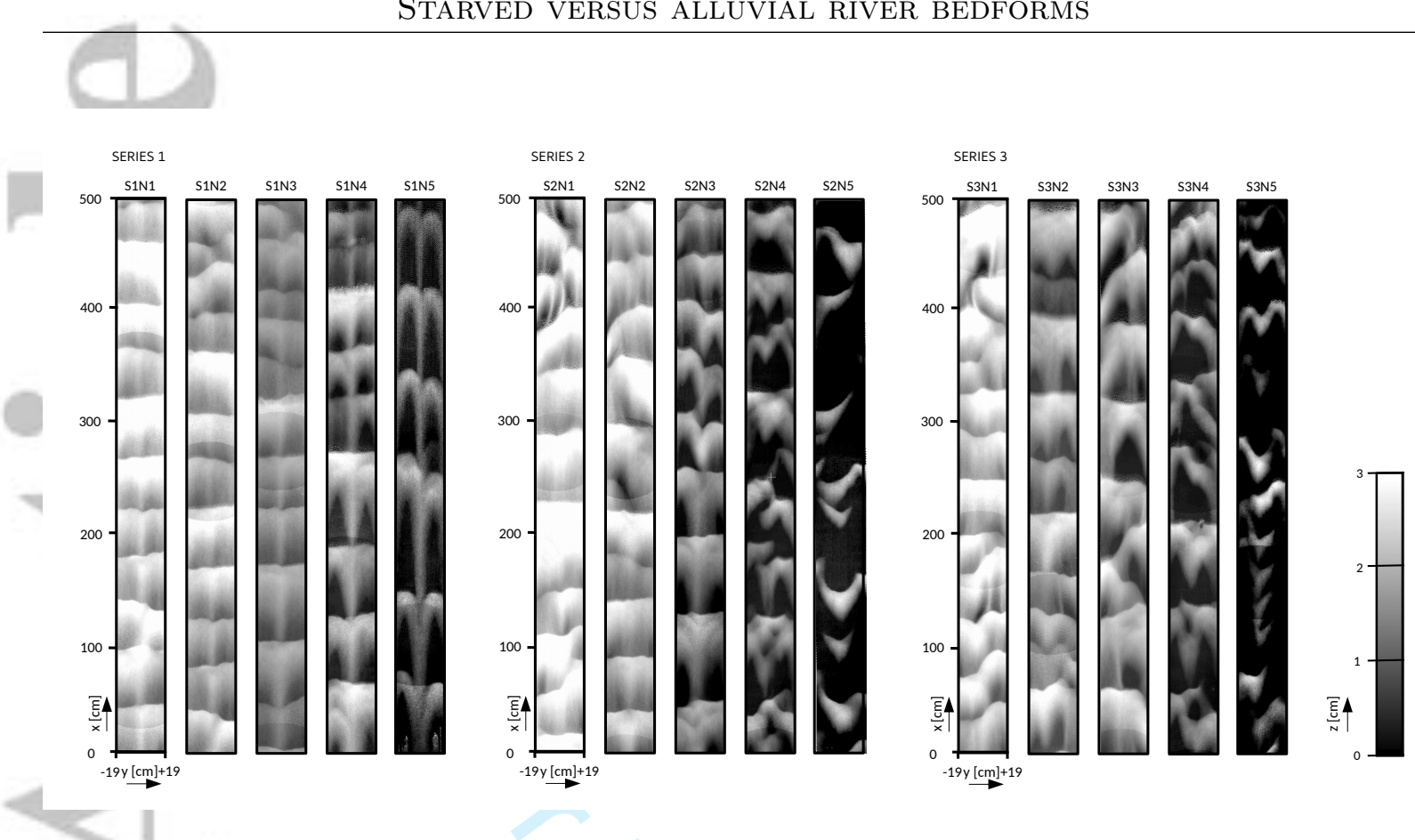

Figure 4: Laser scans representing the final bottom configuration within the $5 \mathrm{~m}$ downstream stretch of the channel at the end of each experiment. The bottom elevation, which is measured with respect to the rigid bottom, is shown in shades of grey, lighter colours corresponding to higher values. Rigid bottom level is black. Flow is from bottom to top.

lee side interspersed with flat troughs. In each series of experiments, the average wavelength of the dunes observed in alluvial conditions was approximately the same, while the averaged crest-to-crest distance of the dunes observed in supply limited conditions markedly increased with a decreasing initial sand layer thickness.

Figure 6,8 and 10 show the two-dimensional spectra of the final bottom configurations for the experiments of the first, second and third series, respectively. The modulus of the complex amplitude of each harmonic component of the two-dimensional Fourier transform of the bottom elevation $\left|\eta_{n, m}\right|$ both in the streamwise and spanwise directions is plotted. The top-panel of Figure 6 shows that, in experiment $\mathrm{S} 1 \mathrm{~N} 1$, the $10^{\text {th }}$ streamwise component is characterised by the largest amplitude. Since, in this case, the length of the selected stretch is approximately equal to $4.5 \mathrm{~m}$, the Fourier analysis confirms that the average wavelength of the alluvial dunes is about $0.45 \mathrm{~m}$. Moreover, even though the spanwise components characterised by a transverse wavelength equal to the channel width and its multiples have a non-vanishing amplitude, it appears that the bottom configuration is practically two-dimensional. Similar spectra characterise the outcome of experiments S1N2 and S1N3. As already commented in Section 2, when looking at the results of Figure 6 the reader should note that the length $L$ of the channel stretch where the Fourier decomposition is applied slightly differs from experiment to experiment. In particular, it is important to note that the $10^{\text {th }}$ streamwise component of experiment S1N1 has approximately the same wavelength of the $8^{t h}$ streamwise component of experiment S1N3. The spectra of experiments S1N4 and S1N5 show that the peak harmonic component in the streamwise direction shifts towards lower frequencies as the thickness of the initial sand layer decreases, confirming the lengthening of the dunes under supply limited conditions. The results show also that, in the transverse direction, the largest harmonic component is the second one, which represents the longitudinal sand ridge appearing along the axis of the channel at the end of most of the 
experiments. Finally, the two-dimensional Fourier analysis for the experiments of the second and the third series shows results that are similar to those of the first series, even though a few qualitative differences are present. In general, the increased flow discharge characterising these series makes the final bottom configurations more three-dimensional, resulting into wider spectra. In line with the first series of experiments, the results show that, as the supply limitation increases, the peak harmonic component in the streamwise direction shifts towards lower frequencies and the amplitude of the spanwise components becomes comparable with those of the streamwise components, and in some cases even larger. Regularly spaced transverse dunes progressively disappear, leading to amorphous bedforms (sandy mounds) that are characterised by a more irregular spacing in the streamwise direction. For the smallest value of the initial sand layer thickness, very three-dimensional barchan dunes appear, the transverse dimension of which is approximately equal to the channel width. These barchans are characterised by an abrupt reduction in bedform height. Table 1 summarises the experimental measurements.

\section{Discussion of the results}

The experimental measurements described in the previous section indicate that, when a motionless substratum is exposed by the formation of sand dunes, the lack of mobile sediment strongly affects the bedform morphology. In particular, the dune spacing tends to increase as soon as the rigid bottom of the flume is bared by the formation of the bedforms, the average crest-tocrest distance of which increases as the initial volume of mobile sediment decreases (Figure 11). These findings are in agreement with the field observations of Carling et al. (2000) and with those of Le Bot and Trentesaux (2004), even though the latter were carried out in a coastal region dominated by oscillatory tidal currents. Less information is available in the literature about the effect of sediment starvation on the heights of the bedforms. The experimental observations reveal that, until the rigid bottom of the flume is exposed, the amplitude of the bedforms remains constant. As the motionless substratum starts to be exposed, the height of the starved bedforms experiences a slight increase (Figure 11). Furthermore, progressively decreasing the initial sediment supply, regularly spaced dunes are replaced by amorphous sandy mounds that are more irregularly spaced in the longitudinal direction. A further decrease of the sediment supply eventually results into the appearance of strongly three-dimensional barchan dunes that are characterised by an abrupt reduction in the average bedform height (Figure 11). Similarly, Kleinhans et al. (2002) describe how the supply limitation (sediment starvation) determines the morphology of the bedforms leading to a transition from two-dimensional transverse dunes to three-dimensional barchans.

In contrast, the laboratory observations of Tuijnder et al. (2009) indicate that the sandy patterns interspersed with exposed parts of the rigid bottom of their flume are shorter and more regular than the alluvial ones that develop for similar values of the flow and sediment parameters. There are several possible explanations to this contradiction between laboratory experiments that indeed present many similarities in the set-up.

Firstly, the duration of the experiments of Tuijnder et al. (2009) was remarkably different, depending on the amount of supply limitation. For strong supply-limited conditions, their experiments lasted for a few hours, whereas they were stopped after even more than one day when the coarse layer was completely covered. It is likely that the size of the dunes increased in time reaching equilibrium wavelengths typically larger than those at the first stage of their formation. It is worth noting that alluvial dunes, which develop for extended periods of time, experience longitudinal elongation as a result of different physical mechanisms. These mechanisms have 

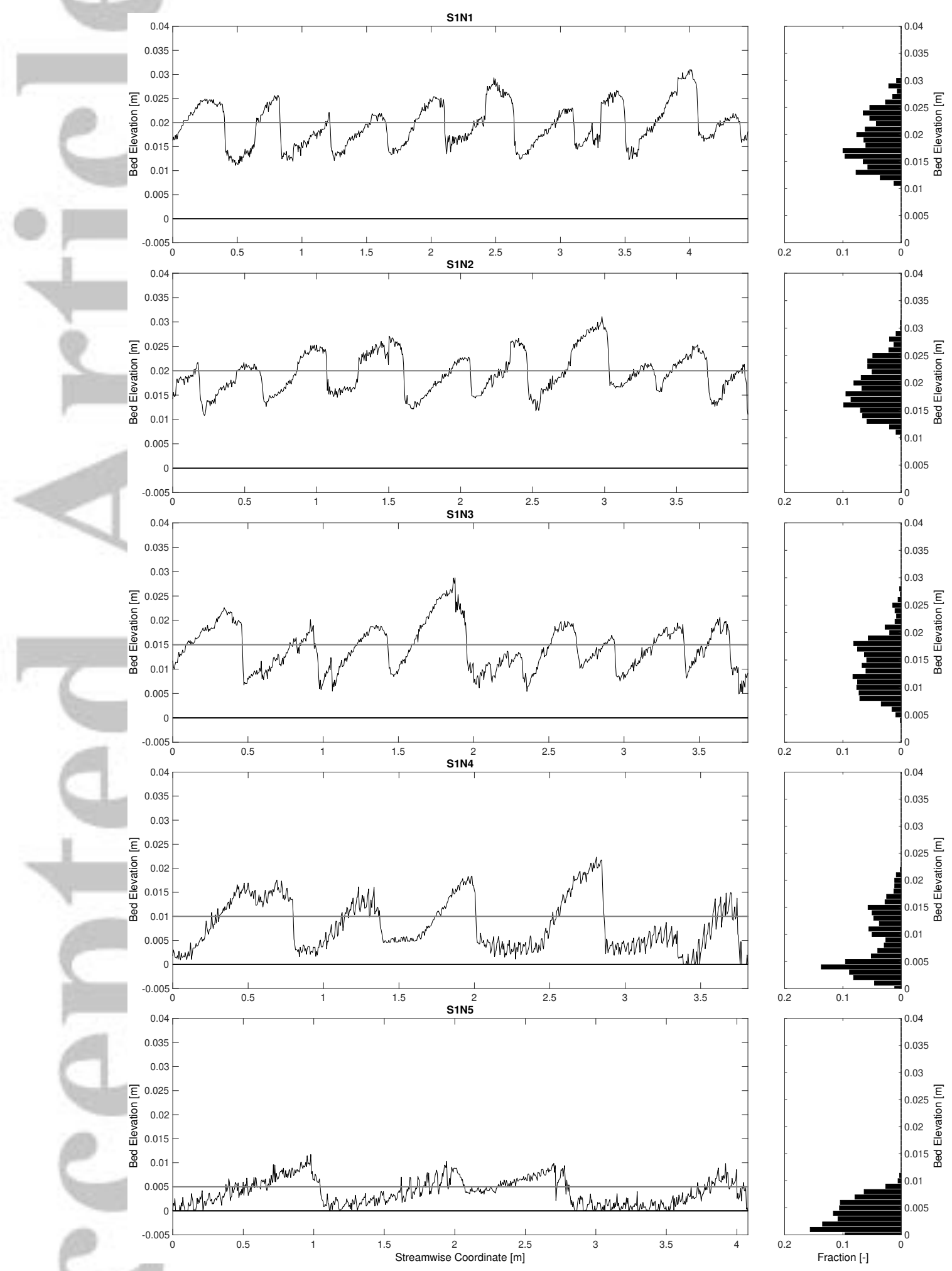

Figure 5: Left panels: bed elevation recorded along a selected stretch of the channel at the end of each experiment of Series 1 (thin black line). The rigid bottom of the flume is represented by the thick black line while the initial level of the sand layer is represented by the thick gray line. Right panels: histogram of the distribution of the bed elevation. 


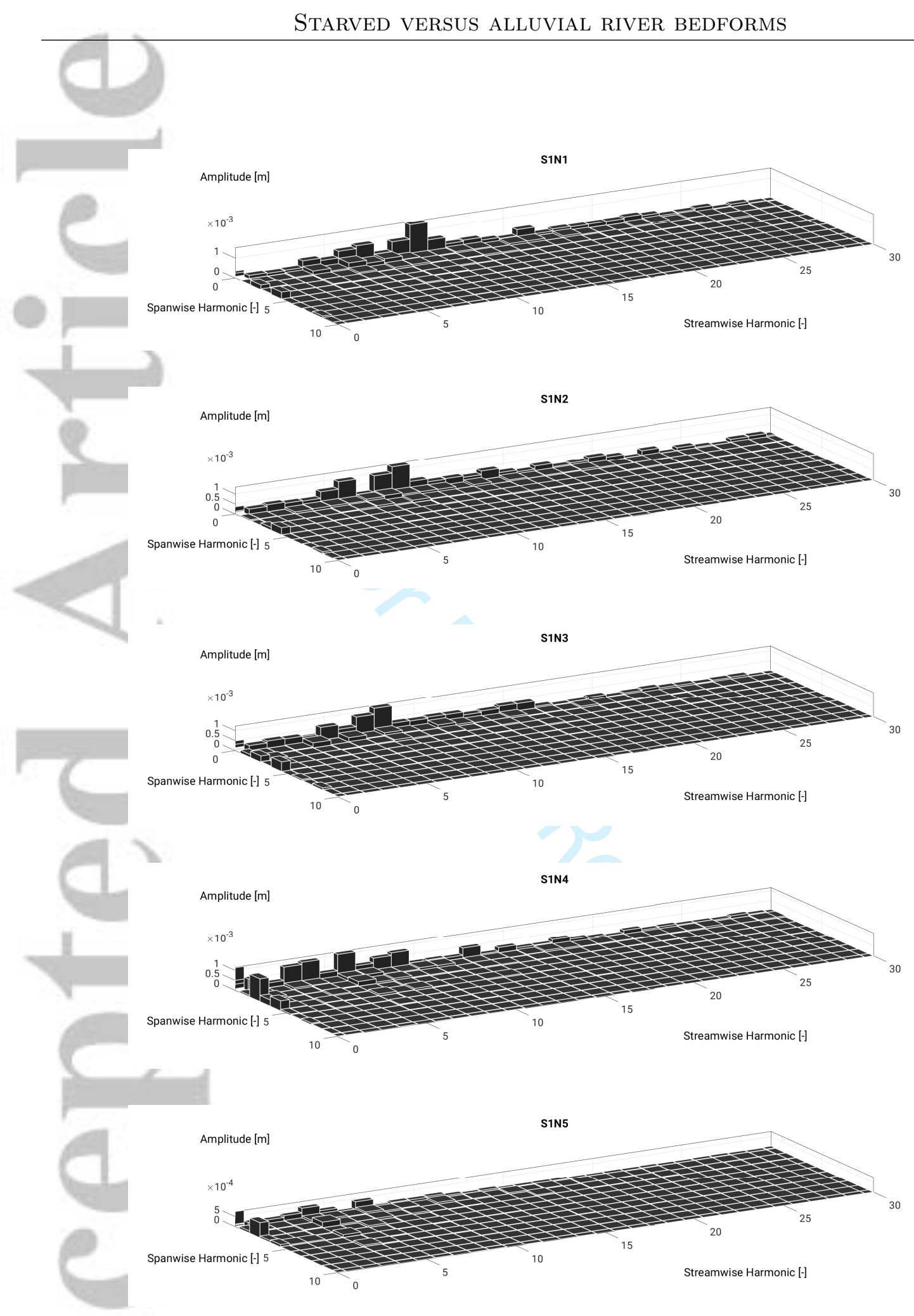

Figure 6: Results of the two-dimensional Fourier analysis of the bottom profile observed along the selected stretch at the end of each experiment of Series 1. The modulus of the Fourier components is plotted versus both the streamwise and the spanwise harmonics. 


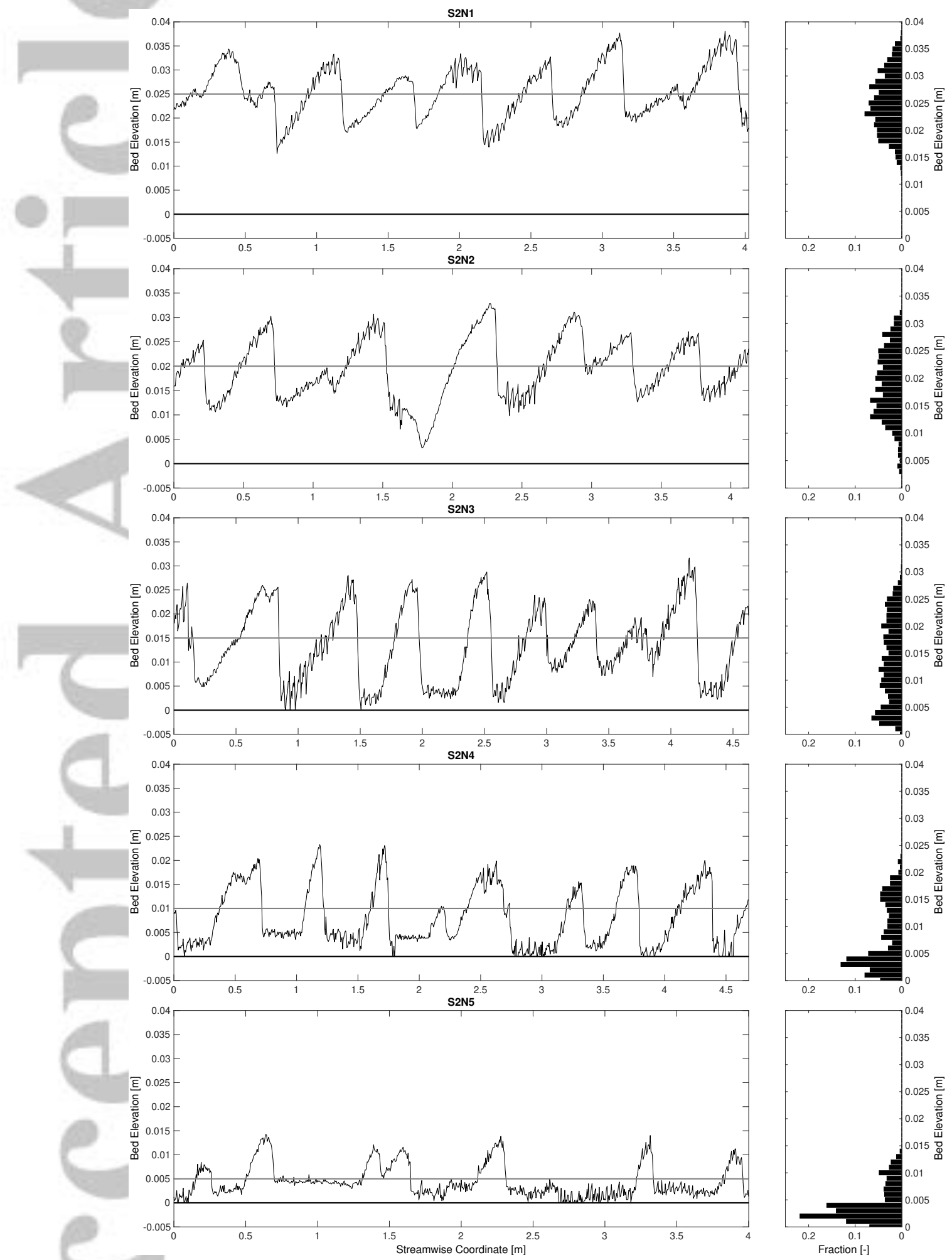

Figure 7: Left panels: bed elevation recorded along a selected stretch of the channel at the end of each experiment of Series 2 (thin black line). The rigid bottom of the flume is represented by the thick black line while the initial level of the sand layer is represented by the thick gray line. Right panels: histogram of the distribution of the bed elevation. 


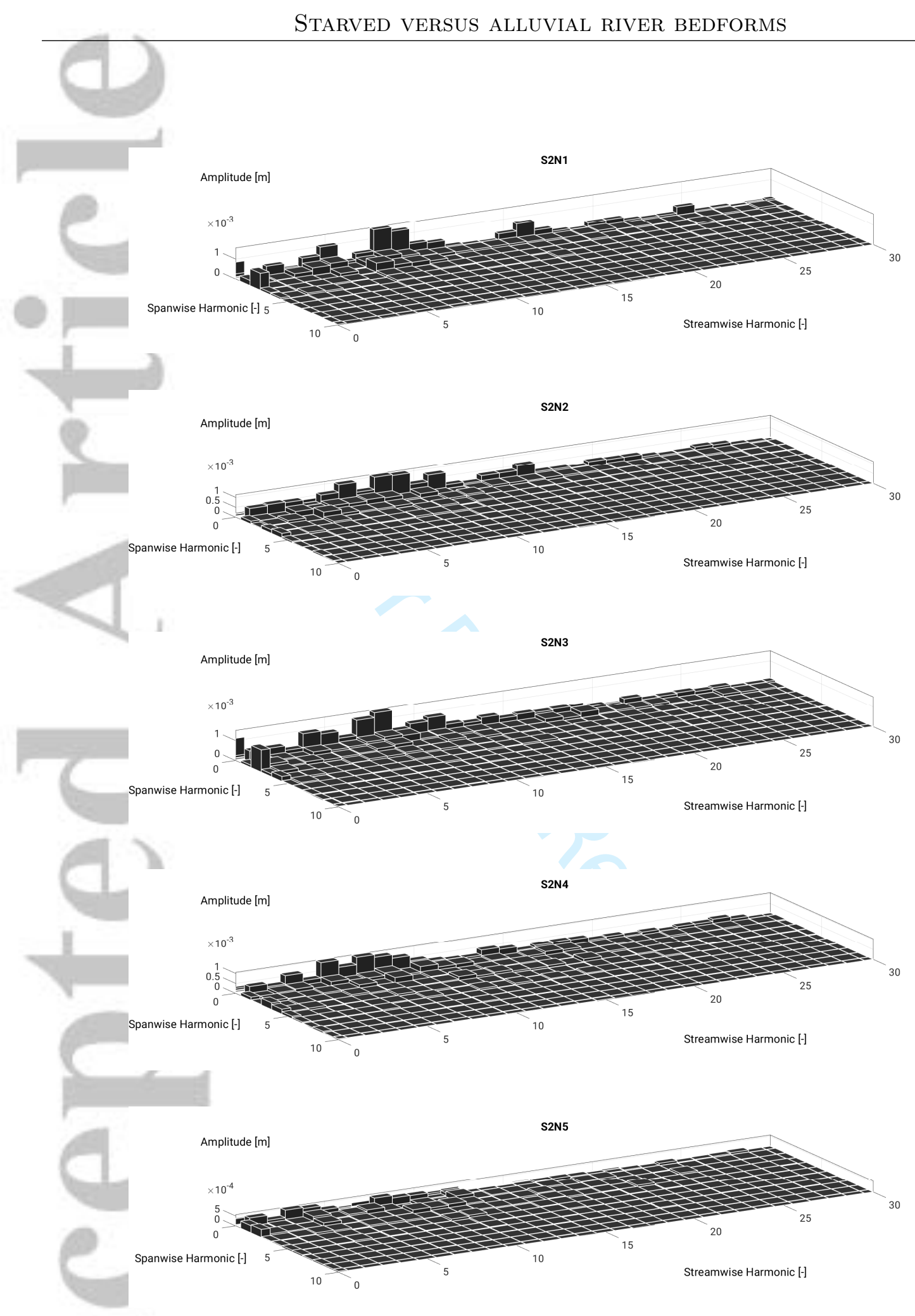

Figure 8: Results of the two-dimensional Fourier analysis of the bottom profile observed along the selected stretch at the end of each experiment of Series 2. The modulus of the Fourier components is plotted versus both the streamwise and the spanwise harmonics. 


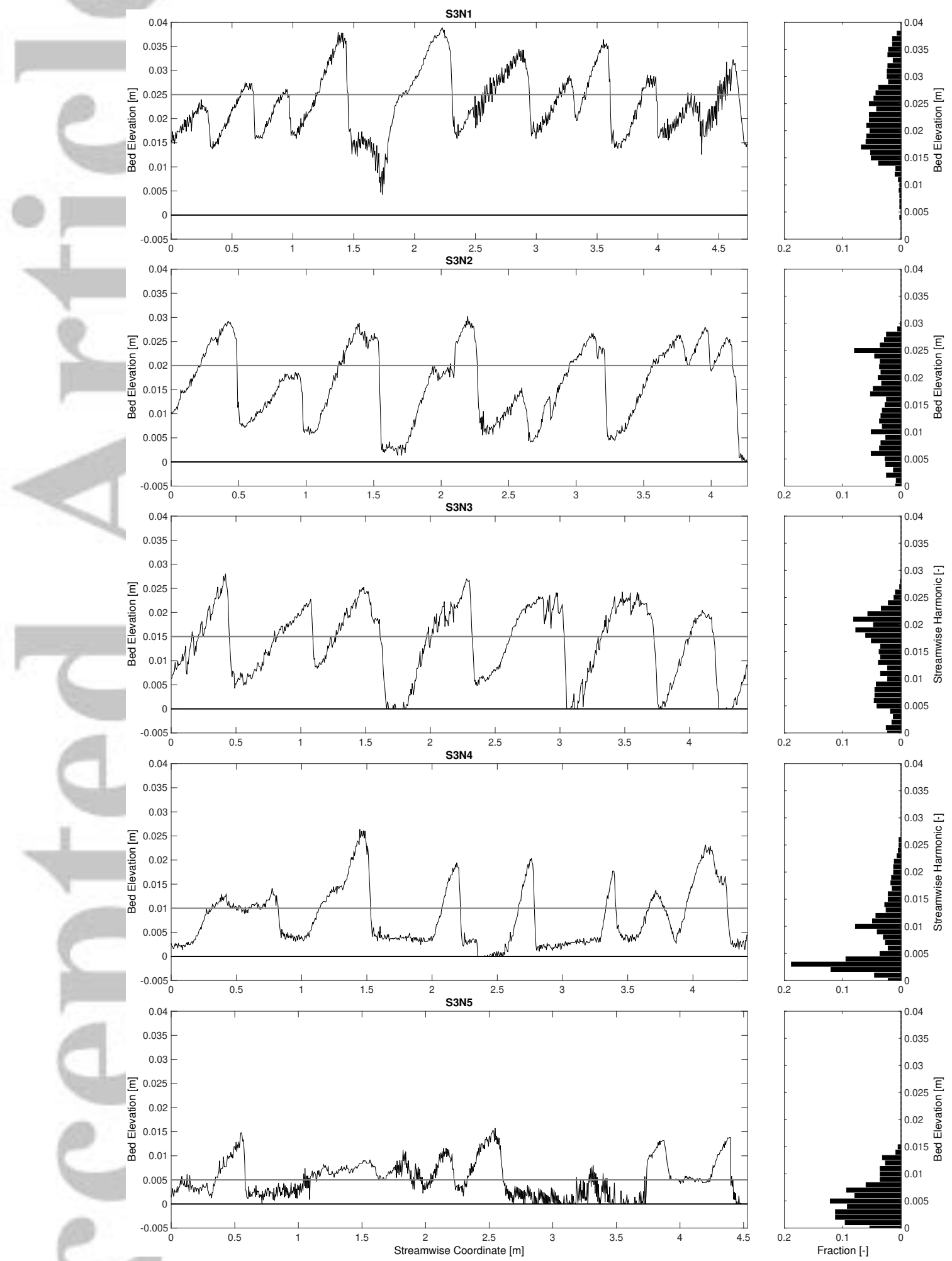

Figure 9: Left panels: bed elevation recorded along a selected stretch of the channel at the end of each experiment of Series 3 (thin black line). The rigid bottom of the flume is represented by the thick black line while the initial level of the sand layer is represented by the thick gray line. Right panels: histogram of the distribution of the bed elevation. 


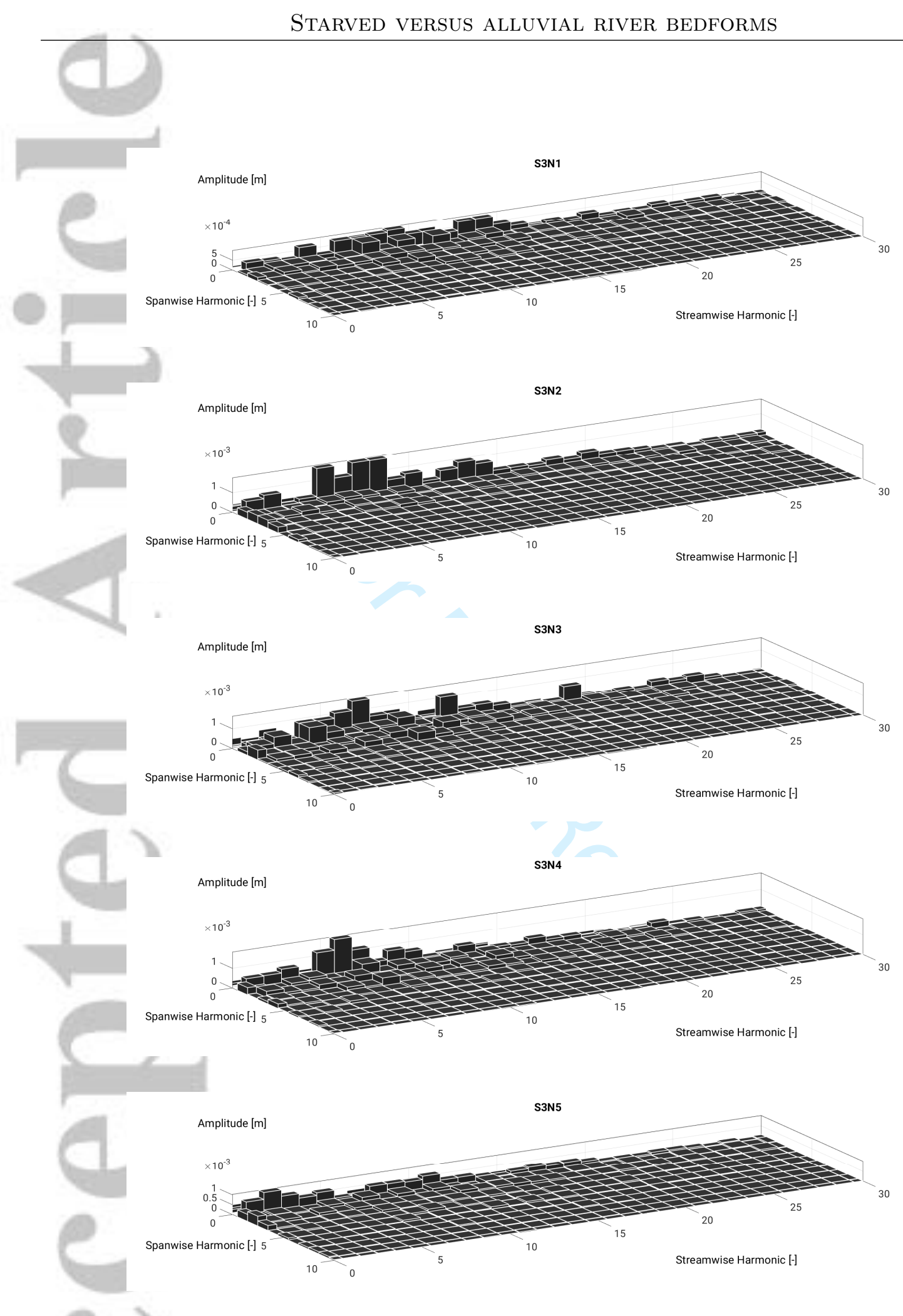

Figure 10: Results of the two-dimensional Fourier analysis of the bottom profile observed along the selected stretch at the end of each experiment of Series 3. The modulus of the Fourier components is plotted versus both the streamwise and the spanwise harmonics. 
been extensively addressed by prior researches. At the very first stage of each experiment of the present investigation, small indentations, similar to those observed by Bagnold (2012), appear throughout the sandy bed and these patterns subsequently elongate as described by the laboratory observations of Coleman and Melville (1994). As discussed in Camporeale and Ridolfi (2011) and Caruso et al. (2016), this initial progressive elongation can be interpreted as a transient growth which eventually will disappear, giving way to much longer bedforms. The latters are the bedforms we observed and measured after half an hour from the beginning of each experiment. The choice of fixing the same duration of the experiments for both the alluvial case and the supply-limited case was made to compare morphological configurations obtained at the same stage of the bottom evolution, thus highlighting the effect of supply limitation alone.

Secondly, two different grain sizes were employed in the experiments of Tuijnder et al. (2009): a coarser one for the motionless substratum and a finer one for the mobile layer. They selected the two sand diameters so as to be sure that the coarser fraction, when exposed to the flow, remained still. As a consequence, the more substrate was exposed during their experiments, the higher the bed roughness becomes. Although it is not clear how the bedform wavelength evolves due to a change of roughness, this surely plays a role in determining size and dynamics of the bedforms. Now, let us consider two ideal experiments, one in the Tuijnder et al. (2009) setup and the other in the present setup. In both experiments the motionless substratum is exposed and the average flow depth is the same, as well as the flow rate, where averaging is intended to be over the crest-to-crest distance of the unit bedform. Hence, the average Froude number is the same in the two configurations, whereas the average bed shear stress, and so the average slope, is higher in the Tuijnder et al. (2009) setup than in the present one, due to the increase in roughness.

Thirdly, the width of the flow cross-section in the experiments of Tuijnder et al. (2009) was more than twice that of the present experiments while the mean flow depth was approximately the same. Such a difference in the width-to-depth ratio can strongly affect laboratory measurements as in narrower flumes the occurrence of transverse modes is inhibited. For values of this crucial parameter exceeding a critical threshold, Colombini et al. (1987) described the tendency of the bottom perturbations to form diagonal fronts, eventually leading to alternate bars, the longitudinal wavelength of which turns out to be much larger than those of typical fluvial dunes.
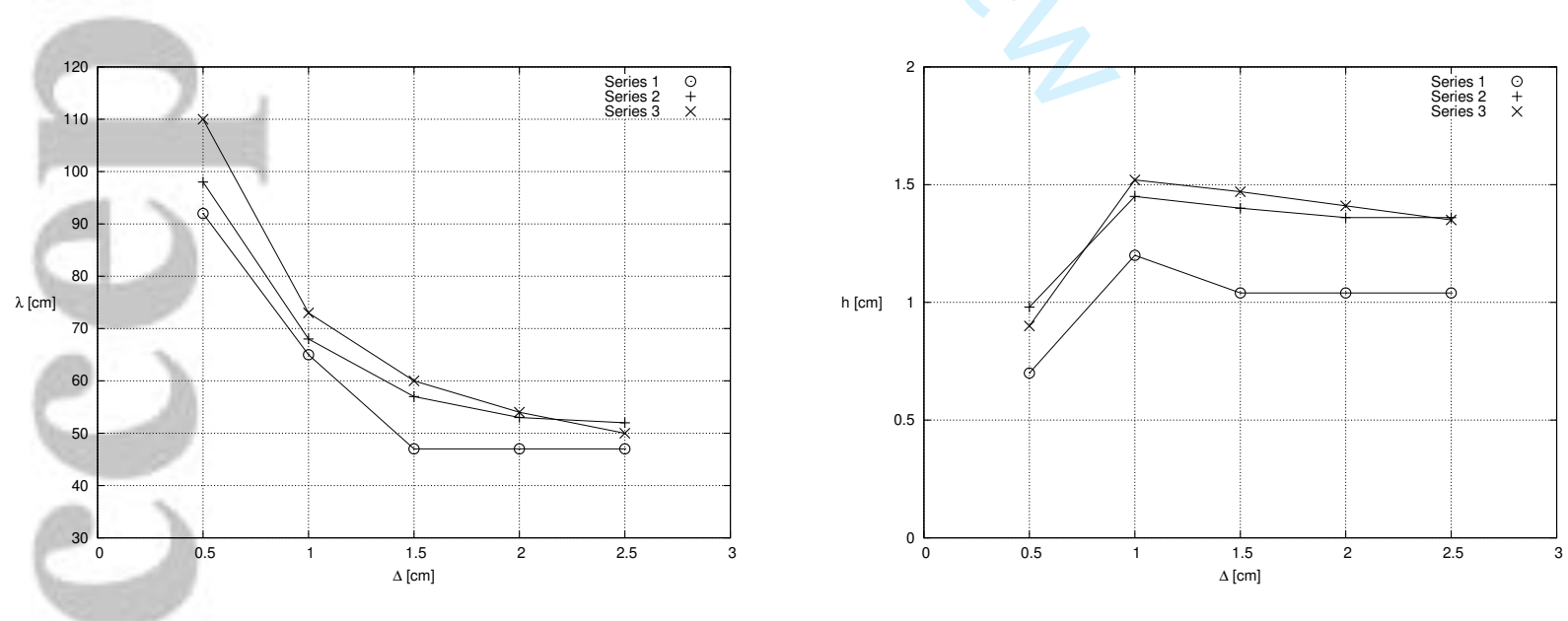

Figure 11: Wavelength $\lambda$ (left panel) and height $h$ (right panel) of the bottom forms plotted versus the thickness $\Delta$ of the sand layer initially present over the rigid bottom. 


\section{Conclusions}

Laboratory experiments were performed to investigate the formation of starved river bedforms. The experimental setup was carefully designed to focus on the role played by sediment starvation neglecting effects due to sediment sorting and amplitude time-development.

Measurements of the bottom profile of both alluvial bedforms and starved bedforms, for the same values of the hydrodynamic and morphodynamic parameters and, in particular, for the same duration of the experiments, show that starved bedforms attain longer crest-to-crest distances and show more irregular, three-dimensional planforms than alluvial bedforms. This is consistent with the field surveys of Carling et al. (2000) and with the laboratory observations of Kleinhans et al. (2002) and Venditti et al. (2017), even though Tuijnder et al. (2009) found qualitatively different experimental results.

When strong supply-limited conditions are enforced, three-dimensional patterns characterised by a high irregularity appear, making it difficult to identify a well-defined wavelength of the bedforms. Indeed, as the initial sediment availability decreases, alluvial dunes are replaced by starved dunes that then disperse in the form of amorphous sandy mounds eventually leading to the emergence of barchan dunes. In order to properly describe the geometrical characteristics of these enigmatic patterns, we performed a two-dimensional Fourier decomposition of the bottom configurations observed at the end of each experiment. This allows for a suitable comparison between alluvial and starved patterns.

Further insights into the formation of starved river bedforms could be obtained either by new laboratory experiments or by numerical simulations possibly based on the procedure outlined in Porcile et al. (2017), who evaluated the flow field over tidal starved bedforms by means of a perturbation approach founded on the assumption that the amplitude of the bottom forms is much smaller than the local water depth. After an appropriate validation, the numerical model would allow for an exhaustive investigation of the effects that sediment starvation has on the formation of fluvial dunes spanning the whole parameter space.

\section{Acknowledgements}

This research was supported by the Ministry of Education, University and Research (Italy), in the framework of Research Projects of National Interest (PRIN 2017), with grant number 20172B7MY9, project 'FUNdamentals of BREAKing wave-induced boundary dynamics'.

\section{Data availability statement}

Research data are not shared. Nevertheless the data supporting the findings of this study are available from authors upon request.

\section{Conflict of interest statement}

The authors declare no conflicts of interest.

\section{References}

Allen, J. L. (1968). Current ripples. 
Bagnold, R. A. (2012). The physics of blown sand and desert dunes. Courier Corporation.

Camporeale, C. and Ridolfi, L. (2011). Modal versus nonmodal linear stability analysis of river dunes. Physics of Fluids, 23(10):104102.

Carling, P., Golz, E., Orr, H., and Radecki-Pawlik, A. (2000). The morphodynamics of fluvial sand dunes in the river rhine, near mainz, germany. i. sedimentology and morphology. Sedimentology, 47(1):227-252.

Caruso, A., Vesipa, R., Camporeale, C., Ridolfi, L., and Schmid, P. J. (2016). River bedform inception by flow unsteadiness: A modal and nonmodal analysis. Physical Review E, 93(5):053110.

Coleman, S. E. and Melville, B. W. (1994). Bed-form development. Journal of hydraulic engineering, 120(5):544-560.

Colombini, M., Seminara, G., and Tubino, M. (1987). Finite-amplitude alternate bars. Journal of Fluid Mechanics, 181:213-232.

Howard, A., Morton, J., GAD-EL-HAK, M., and Pierce, D. B. (1978). Sand transport model of barchan dune equilibrium. Sedimentology, 25(3):307-338.

Kenyon, N. H. (1970). Sand ribbons of european tidal seas. Marine Geology, 9(1):25-39.

Kleinhans, M., Wilbers, A., De Swaaf, A., and Van Den Berg, J. (2002). Sediment supply-limited bedforms in sand-gravel bed rivers. Journal of sedimentary research, 72(5):629-640.

Le Bot, S. and Trentesaux, A. (2004). Types of internal structure and external morphology of submarine dunes under the influence of tide-and wind-driven processes (dover strait, northern france). Marine Geology, 211(1-2):143-168.

Nezu, I. and Nakagawa, H. (1984). Cellular secondary currents in straight conduit. Journal of hydraulic engineering, 110(2):173-193.

Parker, G., Klingeman, P. C., and McLean, D. G. (1982). Bedload and size distribution in paved gravel-bed streams. Journal of the Hydraulics Division-Asce, 108(HY4):544-571.

Porcile, G., Blondeaux, P., and Vittori, G. (2017). On the formation of periodic sandy mounds. Continental Shelf Research, 145:68-79.

Sophie, L., Trentesaux, A., Garlan, T., Berne, S., and Chamley, H. (2000). Influence des tempêtes sur la mobilité des dunes tidales dans le détroit du pas-de-calais. Oceanologica Acta, 23(2):129-141.

Tuijnder, A. P., Ribberink, J. S., and Hulscher, S. J. (2009). An experimental study into the geometry of supply-limited dunes. Sedimentology, 56(6):1713-1727.

Venditti, J. G., Nelson, P. A., Bradley, R. W., Haught, D., and Gitto, A. B. (2017). Bedforms, structures, patches, and sediment supply in gravel-bed rivers. Gravel-bed rivers: Process and disasters, 439 .

Wippermann, F. and Gross, G. (1986). The wind-induced shaping and migration of an isolated dune: a numerical experiment. Boundary-Layer Meteorology, 36(4):319-334. 